\title{
Scopes, Options, and Horizons - Key Issues in Decision Structuring
}

\author{
Sven Ove Hansson ${ }^{1}$
}

Accepted: 6 March 2018 / Published online: 3 April 2018

(C) The Author(s) 2018

\begin{abstract}
Real-life decision-making often begins with a disorderly decision problem that has to be clarified and systematized before a decision can be made. This is the process of decision structuring that has largely been ignored both in decision theory and applied decision analysis. In this contribution, ten major components of decision structuring are identified, namely the determination of its scope (the issues to be covered by the decision), subdivision (if and in that case how the decision will divided into separate parts), agency (who will make the decision), timing, options, control ascriptions, framing, horizon (the consequences and other aspects of outcomes that will be taken into account), criteria (of success) and (provisions for) restructuring. Four of these components, namely the scope, subdivision, options, and horizon of a decision, are subjected to a more detailed analysis.
\end{abstract}

Keywords Decision structuring · Great uncertainty · Background decisions · Framing · Control · Timing

\section{Introduction}

In moral philosophy, decision theory, and the applied decision disciplines it is standardly assumed that decision problems are well defined. Most real world problems are much more open-ended. In many decision situations, it is not settled from the beginning exactly which issues should be decided upon, what options there are, how we should judge to what extent the decision was successful, etc. This has to be settled in the course of the decision-making process. Since the decision sciences have their focus on decision problems in which all of this has already been determined, they do not provide much guidance for these components of decision-making. ${ }^{1}$

\footnotetext{
${ }^{1}$ However, interesting discussions on how to set up a decision can be found for instance in Jeffrey (1976), Resnik (1987, ch. 1) and Seidenfeld 1994.
}

Sven Ove Hansson

soh@kth.se

1 Royal Institute of Technology, Stockholm, Sweden 
Early theoretical studies of decision-making did not always have this one-sided focus on choices among well-defined and already evaluated alternatives. For instance, in a preparatory text for the French constitution of 1793, Condorcet divided decision-making into three phases. In the first of these, one "discusses the principles that will serve as the basis for decision in a general issue; one examines the various aspects of this issue and the consequences of different ways to make the decision." At this stage, the opinions are personal, and no attempts are made to form a majority. In the second phase "the question is clarified, opinions approach and combine with each other to a small number of more general opinions." The third stage consists of the actual choice of one of these alternatives. (Condorcet, [1793] 1847, pp. 342-343) This is the part of the process that modern decision theory and its applied variants focus on. The first two stages are largely concerned with determining the structure of the decision: the issue(s) to be settled, whether there will be one single decision point or several subdecisions, what options will be available etc. I propose to call the process of settling these issues the structuring of a decision. It precedes, and prepares for, the well structured decision problems that are the usual topic of decision theory.

Section 2 provides an account of the components of decision structuring. Four components that are particularly important for decisions on risks are singled out for a more detailed treatment, namely: the scope, subdivision, options, and horizon of the decision (Sections 36). The major conclusions of are summarized in Section 7.

\section{The Components of Decision Structuring}

The following are ten major components of decision structuring.

1. Scope: The scope of a decision is its decision matter, i.e. the totality of issues that will be covered by it. The scope is often limited by background decisions that are (rightly or not) assumed to be unalterable.

2. Subdivision: Decisions on complex issues are often divided into several smaller parts.

3. Agency: It is not always clear from the beginning of the process who will make the $\operatorname{decision}(\mathrm{s}){ }^{2}$

4. Timing: In most formal approaches to decision-making, the timing is either assumed to have been settled beforehand, or entirely abstracted from. In practice, determining the time-scale of one's own decision is often a crucial component of decision-making. (Hirsch Hadorn 2016)

5. Options: The identification (and sometimes construction) of the options available to be chosen is an important component of the early phases of decision-making. ${ }^{3}$

\footnotetext{
2 The term "agency" is used here to refer to the capacity to make decisions. It was chosen for lack of a word that covers that meaning better.

${ }^{3}$ The set of options is limited by the scope of the decision, but it can also have additional limitations. To exemplify this, suppose that you are visiting a small café that only serves tea, coffee, pretzels, and Danish pastries.
}

Case a: You are offered a choice between coffee with a Danish pastry and tea with a pretzel.

Case b: You are offered a choice between coffee with a Danish pastry, coffee with a pretzel, tea with a Danish pastry, and tea with a pretzel.

Your decisions in these two cases have different sets of options (with two respectively four elements), but the scope (decision matter) is the same, namely what to eat and drink in this café. 
6. Control: The degree of control that agents are assumed to have over their own future actions can have a large impact on decision processes and their outcomes. ${ }^{4}$

7. Framing: Several studies have shown that our decisions are influenced by how the options or the background conditions are described. The choice how to describe a given decision and its options is called the framing of the decision. (Grüne-Yanoff 2016)

8. Horizon: In order to evaluate the decision options, we need to determine what properties of the potential decision outcomes will be taken into account.

9. Criteria: When the horizon of the decision has been determined, it remains to decide how the various aspects included in the horizon should be evaluated. Such evaluation criteria usually take the form of decision rules (decision principles) that are closely connected with how we conceive the nature and structure of (moral) values. (Hansson 2016)

10. Restructuring: It is not uncommon for decisions to be restructured in the course of decision-making. Decision processes differ in the degree to which such restructuring is facilitated or impeded.

As the terms "scope" and "horizon" are used here, the scope is the set of issues that are decided upon, whereas the horizon is the set of aspects that are "seen" or taken into account in the decision. These definitions have support in general usage. According to the Oxford English Dictionary, by scope can be meant "[t]he sphere or area over which any activity operates or is effective" or the "[r]oom for exercise, opportunity or liberty to act". The same source gives as a meaning of horizon: "that which bounds one's mental vision or perception; limit or range of one's knowledge, experience, or interest".

There are many interdependencies among the ten components. For instance, the subdivision of a decision refers to its scope, the criteria refer to the horizon, and its timing and its subdivision are interdependent. Therefore, deliberations on the structuring of a decision should not follow any strict linear pattern.

The structuring of a decision can often be modelled as a set of separate decisions. However, some of the components of structuring do not seem to be directly accessible to traditional decision-theoretical modelling. This applies prominently to ascriptions of control and to the innovative process of finding or inventing new options.

Furthermore, an attempt to capture structuring within a traditional decision-making framework will run the risk of infinite regress. If structuring is determined in a pre-decision, then it can legitimately be asked how this pre-decision should be structured, and this can lead us to introduce a pre-pre-decision for that purpose, etc. However, as was indicated by Resnik (1987, pp. 10-12), such infinite regress can be avoided if decision costs are taken into account. After a (probably small) number of steps backwards in the chain, the gains from detailed analysis of such additional steps will expectedly be so small that an immediate decision based on gut reactions will be the better option.

Four of the above ten components are particularly fundamental for decision-making. The scope of the decision matter, its subdivision, and its partitioning into options determine what the decision maker can choose between. The horizon determines what considerations are included in her deliberations on this choice. I have therefore selected them for a more detailed analysis.

\footnotetext{
${ }^{4}$ When the decision is represented in a conventional decision matrix, potential states of affairs that the decision maker has control over will be parts of the decision option, whereas states of affairs outside of the decision maker's control will typically be parts of the states of nature.
} 


\section{Scope}

Most decisions can be demarcated in many different ways. When deciding where to go for a bicycle vacation you can either make a detailed itinerary beforehand, or just decide where to start, and then decide the rest as you go on. In this and other examples the detailed and the less detailed alternative can be described as decisions with different scopes, but they can also be described as decisions with the same scope that can either be subdivided or made on a single occasion. The individuation of a "decision" is unclear, i.e. there is often no definite answer to whether a decisional process should be described as a single decision or as a collection of several connected decisions.

\subsection{Background Decisions}

When we determine the scope of a decision we draw a line between that which we treat as open for us to determine and the various background conditions of the decision. For instance, policy decisions on nuclear waste disposal have been discussed with reference to each of the following five scopes:

- How should we safely dispose of the radioactive waste that has already been produced and will be produced in the future?

- How should we safely dispose of the radioactive waste that has already been produced?

- Given the system that we have for the distribution and consumption of energy, how should we produce energy? Should we do it in a way that leads to the production of additional nuclear waste?

- Given the rest of our social system, how should we produce, distribute, and consume energy? Should we do it in a way that leads to the production of additional nuclear waste?

- How should our society and consequently our energy system be arranged? Should we organize them in a way that leads to the production of additional nuclear waste? (Hansson 1996)

These ways to conceptualize decision-making about nuclear waste serve different interests and purposes. People who wish to close down nuclear power prefer to discuss the waste issue in a perspective that does not take the continued use of nuclear energy for granted. Proponents of the continued use of nuclear energy prefer perspectives that isolate the nuclear waste issue from these broader topics.

This example exhibits a general pattern: The chosen scope determines what we treat as decision matter, i.e. as issues to be settled one way or the other in the particular decision. Obviously, circumstances that the decision maker has no means to influence should not be included in the decision matter, but often much more than so is excluded. Among the excluded matter there is often a set of background decisions, i.e. circumstances that depend on previous decisions (or previous choices not to make a decision) that it would be possible to revoke but are nevertheless treated as unalterable background conditions. In the case of nuclear waste, the most prominent background decisions are those that lead to the use of nuclear power plants. In other cases, the relevant background decisions may be less obvious. Like other decisions, background decisions are typically based on values. Their impact on the scope of a decision can therefore take the form of "hidden" value assumptions that influence the decision. It is essential that background decisions are brought to light and explicitly discussed. One possible outcome of such deliberations can be that the scope is extended to include reconsideration of some of the background decisions. 


\subsection{Causality and Responsibility}

The identification of the cause(s) of an event or potential event often has a decisive role in the demarcation between background decisions and the decision matter to be decided upon. Causality ascriptions can legitimately be made in different ways, and they are certainly not completely dictated by the nature of things. Mill ([1843] 1996, 327-334) showed convincingly that although events typically follow from several causal factors, we tend to single out one of these factors as "the cause" of the event, treating the others as background conditions. Several considerations influence which causal factor we choose to call "the cause": how certain we are of its influence, its salience or conspicuity, whether it could plausibly have been absent, and whether it could have been changed by human action. (Hoover 1990) Our causal ascriptions are largely based on social conventions and traditions, but in many cases they will change with the context. For instance, if you ask a bacteriologist what is the cause of cholera you can expect the answer "the bacterium Vibrio cholera", but from a public health expert you would probably receive the answer "lack of proper sanitation". For decisions on the treatment of cholera patients the former answer may be the most adequate one, whereas the latter would be more useful for decisions on disease prevention.

As one example of this, most traffic accidents have causal factors pertaining to both the behaviour of the driver and the construction of the vehicle. For instance, a driver's decision to drive drunk or at an illegal speed often contributes to accidents, but so do the rather obvious technical malfunctions of standard cars that they lack alcohol interlocks and automatic speed limiters. When we discuss how to reduce traffic accidents, the drivers' decisions are always included in the scope of the decision, whereas the decisions by regulators and manufacturers to allow respectively market cars without these life-saving technologies are usually excluded. As this example shows, there is a close connection between our ascriptions of responsibility and of (human) causation. If we started to talk about the decision makers who failed to introduce speed-limiters as "responsible" for speeding accidents, then we would probably also describe the lack of these safety devices as "the cause" of the high prevalence of such accidents. Our responsibility ascriptions and our ascriptions of human causality are interdependent, and the latter are by no means immune against influence from the moral beliefs that inform the former.

The effects of causality ascriptions are particularly important for events that have clearly defined victims. In many cases, some but not all of the causal factors leading to the adverse effects are actions by the victim(s). Our analysis of the situation, and in particular the demarcation between the decision matter and its background, will depend to a large degree on whether or not we choose to consider some action by the victim to be "the cause" of the potential adverse effect. (Becker 1986, cf. Needleman 1998 and Burris 1997)

Susan is a famous actress. She is also a very careless person. These are three episodes from her life:

(1) Once when she attended the Royal Ascot she was one of hundreds of persons in a big crowd. Most of them were wearing hats, and Susan had a big hat created for her by a famous designer in Paris. When the wind started to blow, everyone else held onto their hats, but Susan did not care to do so. Much to her chagrin, her hat flew away with a gust of wind whereas everyone else managed to keep their headgear in place. 
(2) On another occasion she was walking in a crowded street, dangling her handbag in a conspicuously careless way. A bag snatcher chose her out of hundreds of potential victims. He took her handbag and rushed away with her cash and other valuables.

(3) Late one summer night she walked home from a party in an unusually revealing dress. Although there were a lot of people around, a man assaulted her and attempted to rape her. She was rescued by bystanders who also handed over the assailant to the police. Questioned by the police, the man said that her skimpy dress had made him target her among the hundreds of women walking alone in the streets that evening.

In all three cases, there were several causal factors contributing to the undesired event, and one of these causal factors was an action or omission by Susan. In the first case, I believe that most of us would describe the loss of the hat as caused by Susan, and therefore also hold her responsible for it.

In the second case we would presumably reason differently. Instead of describing the theft as caused by Susan's careless behaviour we would ascribe this role to the much more reprehensible act committed by the mugger. Importantly, it is for ethical reasons that we single out his action rather than Susan's as "the cause", and therefore our choice of "the cause" cannot be reconstructed in value-free terms. In particular, it cannot be explained in probabilistic terms. We can suppose that there were so many muggers around that it was almost certain that someone carrying a bag as carelessly as Susan did would lose it. In that case, the probability of her losing the bag would not have decreased much if this particular mugger had decided not to take it, but it would have decreased dramatically if Susan had followed standard advice on how to avoid getting mugged. This example shows that in a choice among a set of causal factors we have a strong tendency to give a culpable rather than an inculpable act the role of "the cause" of an undesirable event.

In the third case it would, according to the general consensus, be outrageous to assign causality to Susan's behaviour. Just as in the second case, the reason for this is ethical, and it cannot be overturned for instance by arguments on how the risk (probability) of being assaulted was increased by one or other aspect of her behaviour. It is the ethical affirmation that Susan and everyone else has an unconditional right not to be assaulted that makes it inappropriate to assign causality to her behaviour. ${ }^{5}$

In the case of the lost hat, a discussion on how to avoid similar events in the future would expectedly conclude fairly swiftly with an advice to Susan and others to hold onto their hats on a windy day. In principle, the problem could be solved by setting up wind shelters at racing courses, but the harm caused by losing one's hat will not be taken to be serious enough to warrant such measures. Therefore, in a discussion on how to avoid losses of hats at race courses, decisions on the construction of the spectators' areas will be taken for granted (i.e. treated as background decisions), and the focus will be on what the spectators can do in order to avoid losing their hats. In contrast, in the second and in particular the third case it would

\footnotetext{
${ }^{5}$ As was pointed out to me by an anonymous referee, we might not find fault with a forensic psychiatrist who, after careful evaluation of the perpetrator's mental reaction pattern, concluded that his attack was caused (or triggered) by the dress. However, in order not to be misunderstood, the psychiatrist would have to state with utmost clarity that this should not be interpreted as a claim that Susan was responsible for what happened. We can in some cases separate human causality from responsibility, but only with difficulty since they are normally closely associated.
} 
seem utterly inappropriate to limit the decision scope to the decisions by potential victims on how to reduce the risk of being victimized.

In recent discussions on healthcare policies, much attention has been devoted to the patients' own responsibilities. Claims have been made that patients who are themselves responsible for their disease should have less insurance coverage than others, or no coverage at all. Such proposals have referred for instance to patients with smoking-related diseases (Stegeman et al. 2014. Andersen and Nielsen 2015.) and alcoholics in need of a liver transplant (Thornton 2009. Leong and Im 2012. Donckier et al. 2014.). It has also been proposed that patients who caused their own disease should be assigned a position further down in healthcare queues such as queues for transplantation. (Johri and Ubel 2003. Waller 2005. Thornton 2009.) However, these proposals tend to be based on oversimplified and largely erroneous views of causality. To begin with, there is no clear demarcation of diseases "caused by" the patient's behaviour. The major diseases referred to in this context, such as coronary heart decease and various cancers, all have complex causal backgrounds with many contributing factors. Smoking substantially increases the risk of coronary heart disease, but such disease is also quite common among persons who have never smoked. It is impossible to determine whether or not a particular smoker would have contracted the disease if (s)he had not smoked. (Indeed, the meaningfulness of such a counterfactual statement could be put to question.) Smoking also increases the risk of a long list of cancers. For some of these, the risk increase is dramatic. For instance, the probability that a nonsmoker contracts lung cancer is between $1 / 30$ and $1 / 15$ of the probability that a smoker does so. At the other end, there are some cancers for which a non-smoker has about $2 / 3$ of the risk that the smoker has. (Sasco et al. 2004) Just as for cardiovascular disease, it is impossible to determine whether or not a particular smoker who contracted a cancer would also have contracted it if she had not smoked. In these and most other cases it is impossible to draw a line between diseases caused and not caused by the patient's own actions. Furthermore, even to the extent that a disease can be attributed to the patient's behaviour, that behaviour may be caused in part by the actions of others. For instance, an inadequate diet may be associated with social factors such as poverty, lack of information, and social pressures and incentives. The same applies to other components of a person's so-called life-style.

Promiscuity is counted as a life-style factor (e.g. Hartung et al. 2002), and cancers that are more common among people with many sexual partners are considered to be life-style diseases (Troyer 1988). Presumably, such cancers would be candidates for being treated as caused by the patient's behaviour. However, there are also at least three forms of cancer, namely breast, ovarian, and uterine cancers, that are more common among sexually non-active women than among those who are sexually active (largely due to nulliparity). Consequently, nuns run a larger risk of these diseases. (Britt and Short 2012) These diseases would therefore have to be classified as life-style diseases in the same sense as the increase of other cancers in promiscuous women. But hopefully, no one would propose that we should to tell a nun with one of these diseases that she has a lifestyle disease for which she must herself be held responsible. The reason for this is of course that we consider celibacy to be a much more morally acceptable behaviour than promiscuity.

As these examples show, the close connections between our ascriptions of responsibility and of (human) causality is a major avenue for the impact of moral values on the scope of a decision. Decision agendas often focus on what are conceived as the causes of the problem to be solved. This is usually taken to be a value-neutral and therefore uncontroversial approach. However, the dependence of causality ascriptions on responsibility ascriptions gives us reason to dispute the assumed value neutrality. 


\section{Subdivision}

The subdivision of the decision matter, i.e. if and then how we divide it into several decisions, can have a large impact on the decision outcome.

Decisions on the allocation of money for public infrastructure investments can be made by parliament in a detailed manner. Alternatively, the details can be decided region per region, or they can be organized according to types of infrastructure (dam repairs, increased road capacity, wastewater and storm water systems, etc.)

This example shows that we have a choice not only between taking decisions in smaller or larger parts, but also between different ways to subdivide them into smaller parts.

In some cases, the decision structure is strongly connected with an organizational structure, and some changes in the former may be impossible without far-reaching changes in the latter.

Decisions on how much we pay for risk reduction are made in many different sectors in society. According to a common view on cost-benefit analysis, such decisions should be coordinated through a single, centralized decision, so that we pay the same sum in all sectors for saving a life. (Hansson 2007. Viscusi 2000, p. 855.)

Such a change would require large changes in the social structure. For example, when a private sector company invests in new machinery or equipment, the investment often both increases efficiency and decreases the risk of workplace accidents. Typically, it has not been determined how much of the cost of the new equipment is paid for increased efficiency and how much is paid for the risk reduction. The proposed co-ordination of all decisions on risk reduction measures would require significant changes in how industrial companies analyse their expenditures.

Arguments on the choice between different ways to subdivide a decision or a decision complex can be divided into three groups according to the type of reason that they refer to: information processing arguments, procedural arguments, and outcome-related arguments.

Information processing arguments refer to the need to keep information processing within the bounds of practicability. Typically, problems with information processing on both the individual and the collective level will point in the direction of subdividing the decision into more manageable parts. In decisions to be made by a single individual such arguments will often refer to our cognitive limitations, and can then be called cognitive arguments. On the collective level, this is often a matter of cognitive division of labour. (Muldoon 2013).

The difficulties in dealing with huge amounts of data form the basis of one of the classical arguments against central economic planning of the production of goods and services. (Vaughn 1980) Similar problems with information processing and co-ordination arise in other processes with highly centralized decision-making. This is a major reason why methods for decentralized (distributed) decision-making have been developed for instance for business management, military operations, and the control of a wide range of complex technological systems. (Sandell et al. 1978; Malone 2004).

At least three types of procedural arguments have bearing on whether and in that case how a decision or decision complex should be subdivided. Competence arguments refer to the advantages of having each part of the decision made by people who understand that part thoroughly. Influence arguments refer to the desirability of including people in 
the decision process who are affected by its outcome. When different groups of people are affected by different parts of a decision, influence arguments tend to provide reasons for subdividing the decision. This is, of course, a major reason to choose local rather than centralized decision-making in issues that are of primarily local concern. It is also an argument for employee participation and co-determination. In many situations, competence arguments will reinforce the influence arguments for subdividing the decision since local residents, employees etc. often have competences and information that higher management does not have. (Hansson and Oughton 2013).

The third type of procedural arguments are the majority seeking and consensus seeking arguments. They refer to the need to organise decisions so that stalemates can be avoided and majorities formed, and/or to the desirability of making decisions with as large majorities as possible. Often, majorities can be formed more easily if several issues are combined into a larger conglomerate. Then a compromise can be made in which all participants have gained something that is important for them. This is perhaps best illustrated by the practice of logrolling and the acceptance of non-germane amendments (riders) in some legislatures. (Gilbert 2006. Carson et al. 2013.) But on the other hand, if only some parts of a complex decision matter are controversial, then a partial consensus can be achieved by subdividing the decision so that its uncontroversial parts are separated from the controversial ones.

Outcome-related arguments, the third major class of arguments concerning the subdivision of decisions, refer to desirable properties of the actual outcome of the decision, rather than to how the decision is made. Obviously, if a decision is controversial, then it will also be controversial which outcomes, or features of outcomes, a decision structure should favour. However, there may be some desirable features of an outcome that can be generally agreed upon, even if no consensus can be reached on other features. Then an agreement can be reached to structure the decision in a way that favours outcomes with the agreed-upon desirable feature(s).

The incomes (taxes) and expenses of a national government can be decided in different ways. One option would be to make separate decisions on each item of the budget, voting tax by tax and expense by expense. However, the standard procedure is to decide on them all on a single occasion.

The reason for this is of course that a subdivision of the budgetary decision would lead to a loss of the legislature's control over the fiscal balance.

\section{Options}

There are two major reasons why the set of options has to be carefully considered in the structuring of a decision: some options may have been forgotten or unnecessarily excluded, and there may also be a need to invent or develop new options.

\subsection{Unpacking Option Packages}

Background decisions often limit the available options to certain "packages" that we need to unpack in order to get a full view of what options are (or could be) available. A famous 
example by Judith Thomson (1986, pp. 189-191) illustrates how background decisions limit the range of available options:

A woman decides to take a shortcut through a dark park at night although she knows that crimes are common in that park. Unfortunately, she is assaulted. In the ensuing trial the perpetrator's attorney argues that her claims for damages should be dismissed or at least substantially reduced since she had herself decided to take the risk of an assault.

Although the victim in this case decided to take a risk of assault, she did not decide to take that risk per se. She chose a package containing this risk and also the benefit of a shorter route (and perhaps some badly needed fresh air). She chose it since there was no other package available that would have given her the same benefit(s) without the associated disadvantage of a risk of assault. She would in all probability not have gone for an option that increased her risk of being attacked but without providing the associated benefits. (This could have been a route through a disreputable dark street with the same increased risk but no time gain, fresh air, or other advantage.) Therefore it would be wrong to say that she opted for the risk of being assaulted. What she chose was a package of time-gain cum risk of assault. What packages she could choose between depended on background decisions such as those by local authorities on police presence, lighting, and opening hours for the park.

In general, when a person takes a risk, she does not usually choose the risk per se, but instead a package consisting of this risk and some advantages that cannot be obtained without it. The moral relevance of that choice has to be judged in relation to what the other packages contain and what influence she had over the process in which the packages were constructed and chosen. A person who makes a choice under circumstances she cannot influence should only be held responsible for the limited choice that she makes, not for the combined effects of this choice and the background decisions that others have made.

A worker takes a job in a mine with many rock falls. This is a job with an unusually high risk of serious injury. When he and his union complain about the high risks, they are countered with the assertion that they have themselves decided to take this job, knowing its dangers.

The workers would not accept this risk alone. They would not be attracted by the prospect of spending eight hours a day in the mine without being paid for it. If there were an alternative job open for them with the same advantages but much lower accident risks, then they would presumably have taken that job instead. Therefore, a discussion on workplace health and safety should not be limited to workers' choice between packages that were constructed in a process on which they had very little influence. Instead, that process should be included in the discussion.

\subsection{Inventing New Options}

Not uncommonly, the best solution to a decision problem remains to be invented. For instance, many environmental and health problems are best solved by technological or social inventions. (Ashford and Hall 2011) Sometimes, this innovative process can be performed as part of the structuring of the decision. However, in most cases it is both time and resource consuming, and will have to be a separate process. Decision structuring should then lead to the specification of 
one or several options that involve such an innovative process. Obviously, this can have considerable impact on the subdivision and the timing of the decision.

\section{Horizon}

The horizon is the outer limit on what we can see from a given point of view. By the decision horizon is meant, in this context, the total set of considerations that are taken into account when evaluating decision outcomes.

\subsection{The Delimitation of Consequences}

Both in decision theory and (consequentialist) moral philosophy, the evaluation of decision options is usually referred to as an evaluation of their "consequences". Unfortunately, the meaning of that term is far from clear. It needs to be clarified in at least four respects. (Hansson 2014).

First, in colloquial usage consequences are taken to be traces of something that happened previously. If there are no traces left of an action in the past, i.e. the world today is the same as it could have been if that action had not been performed, then it has no consequences any longer. However, it would be morally absurd to exclude all effaced consequences, such as forgotten suffering, from moral evaluations. (Kupperman 1980, p. 325) A plausible method for the evaluation of decisions or actions will have to include effaced consequences in its appraisals. This can be done either by treating them as consequences or by evaluating them under some other designation.

Secondly, consequences have often been conceived as not referring to the agency of past actions. If I break an antique vase, then according to this view it will be a consequence of that action that the vase is broken, but not that it was broken by me. Several authors have argued that this is a too limited notion of consequences. (Sosa 1993, p. 112. Sen 2000, p. 489. See also Sen 1983, Skorupski 1995, Scanlon 1998, pp. 88-90, Louise 2004, and Hansson 2014.)

Thirdly, motives and mental causes of actions and decisions have often been excluded. If I break the vase intentionally, then the fact that it was broken intentionally will not be included in a description of the consequences of what I did. This is problematic since our moral evaluations of intentional and unintentional harms tend to differ. (Sen 2000, p. 491. Kupperman 1980, p. 329.)

Robert is a bricklayer working on the roof of a tall building.

Case $i$ : He throws down a defective brick to the ground without first making sure that there is nobody beneath who can be hit by it. Unbeknownst to him, a political demonstration is passing by in the street into which he throws the brick.

Case ii: A political demonstration that he strongly dislikes is marching in the street below the building. Seeing this, he throws down a brick, trying to hit one of the demonstrators. Due to the distance to the ground and his bad marksmanship, the probability that the brick will hit a person is the same as in the previous case. (Hansson 2013, pp. 48-49)

Standard decision analysis does not make a difference between these two cases, but there are obvious reasons why they should be treated differently. 
Fourthly, standard decision analysis does not take into account whether moral obligations are observed or whether rights are respected. This limitation has been criticized for instance by David Sosa who remarked that if an innocent person is hanged to create peace, then the consequences of this action include the violation of an innocent's rights. (Sosa 1993, pp. 101102. See also: Kupperman 1980, p. 325. Pettit 1988. Zamir 2001.)

Standard risk analysis and cost-benefit analysis both employ a limited decision horizon in which agency, intentionality, obligation fulfilment, and respect for rights have no place. From a moral point of view, these are issues that cannot reasonably be dismissed without careful consideration. Therefore, these forms of decision analysis have to be complemented with systematic considerations of wider ethical issues. (Hansson 2017).

\subsection{Spatial, Temporal and Jurisdictional Limitations}

The scope of decision-making is often limited the decision-maker's area of responsibility. A government is supposed to focus on what is good for the country, and a CEO on what is good for the company. But these limitations are often problematic. Consider the following examples:

(1) A factory discharges toxic waste into a river close to the national border. This will have only negligible consequences on the environment within the country, but there will be significant negative consequences in the neighbouring country that the river flows into.

(2) A proposal has been made to build a nuclear reactor close to the national border. Most of the persons at risk in the case of a major accident are inhabitants of a large city in the neighbouring country.

(3) Domestic industries emit sulphur dioxide that has negative environmental consequences in neighbouring countries.

(4) Industries, transportation, heating, and other activities in the country emit greenhouse gases that contribute to global climate change.

(5) A domestic company owns a foreign factory. That factory uses equipment that emits much more greenhouse gases than if modern technology had been used.

(6) A domestic company imports goods from a foreign factory that it does not own. That factory uses equipment that emits much more greenhouse gases than if modern technology had been used.

(7) A domestic company owns a foreign factory. That factory uses dangerous work processes that put workers at acute risk of fatal accidents.

(8) A domestic company imports goods from a foreign factory that it does not own. That factory uses dangerous work processes that put workers at acute risk of fatal accidents.

In most countries, the first four cases would be subject to intervention by the national government. In the other four cases, this is more doubtful. However, it is not obvious on what - if any - principled grounds a limit can be drawn for a country's responsibilities for transborder consequences of its decisions.

A company planning a large road construction project has performed a risk analysis showing that the project will lead to two (statistically) expected deaths in workplace accidents. Opponents of the project call for it to be stopped, using the two expected deaths as one of their main arguments. In response, the company shows that if the same 
number of workers were employed for the same time in other road projects, then the expected number of deaths would be three. The company points out that if this project is stopped then other road projects will receive the funding reserved for it. Therefore, they say, the proposal to stop the project would in fact cost one (statistical) life.

The company in this example extends the decision horizon beyond what is common in discussions of occupational safety. What risk-exposed workers would do otherwise is usually not included in the analysis. This exclusion is far from uncontroversial, but it can be defended with reference to the difficulties of knowing what the workers in question would have done otherwise.

The decision horizon has to stay within a predictability limit that depends on factual circumstances. What we do now may have social consequences hundreds of years into the future, but in most cases we cannot meaningfully assess these consequences, and therefore we have to leave them out. (In contrast, many environmental consequences can be assessed on a rather long time scale, due to the greater predictability of many natural phenomena.) However, within the predictability limit there are many choices to be made, and these choices will largely be value-based. The following are some of the value issues that we may have to consider:

Should we only include "impersonal" consequences, or should person-related aspects such as the agency, purpose, and intentions of decisions and actions be taken into account?

Should the horizon be limited in terms of time or geographical area?

Should the horizon be limited to the jurisdiction in which the decisions are effectuated?

Should the horizon include the consideration of whether moral obligations have been fulfilled and whether rights have been respected?

\section{Conclusion}

In Section 2 we identified ten major components of the structuring subprocess of decisionmaking. In Sections 3-6, four of these components were scrutinized, namely the scope, subdivision, options, and horizon of the decision. The scope depends to a large part on the demarcation between background decisions that are treated as immutable and the decision matter considered to be open for decisions. This delimitation is largely based on social conventions and preconceptions, many of which are value-based. It is also closely connected with value-based responsibilities and causality ascriptions. As we saw in Section 3.2, ascriptions of (human) causality are not as exclusively fact-based as we might wish to believe. To the contrary, the link between responsibility and causality is a major inroad for values into decision structuring.

Our list of potential considerations for the subdivision of a decision includes both procedural and substantial values. To exemplify the former, we may prefer a certain subdivision of a decision because we want to facilitate participation or influence for certain groups of people. If we assign high value to the involvement of local citizens then we can substantially facilitate it by choosing a geographical subdivision. The influence of substantial values is exemplified by the common preference for deciding on a national budget on a single occasion, rather than making separate decisions for each expense and each source of income. The reason why this is preferred is of course the value assigned to fiscal balance. 
In the section on options we found that the list of options in a decision is often limited by background decisions. As already clarified, such background decisions are typically value-based. Furthermore, the choice whether or not to search for, or develop, new options will depend largely on how satisfactory the initially available options are, and that is clearly a value judgment.

Finally, the choice of a horizon for the decision will have to be based on judgments on which consequences and other aspects are important enough to be taken into account, and also on which of these aspects the decision maker is responsible for. These are obviously value judgments.

In summary, this shows that the structuring of decisions is unavoidably value-based. An ethically neutral structuring of practical decisions does not seem to be possible. Since structuring precedes the traditional decision theoretical treatment, this speaks against the common assumption that decision theory needs no other input from ethics than the evaluation of decision outcomes. This can be used as an argument against the conventional demarcation between ethics and decision theory, which is also problematic from other points of view. (Hansson 2010) The role of ethics in decision-making appears to be much larger than what has usually been assumed.

Open Access This article is distributed under the terms of the Creative Commons Attribution 4.0 International License (http://creativecommons.org/licenses/by/4.0/), which permits unrestricted use, distribution, and reproduction in any medium, provided you give appropriate credit to the original author(s) and the source, provide a link to the Creative Commons license, and indicate if changes were made.

\section{References}

Andersen MM, Nielsen MEJ (2015) Luck egalitarianism, universal health care, and non-responsibility-based reasons for Responsibilization. Res Publica 21:1-16

Ashford NA, Hall RP (2011) The importance of regulation-induced innovation for sustainable development. Sustainability 3:270-292

Becker MH (1986) The tyranny of health promotion. Public Health Review 14:15-25

Britt K, Short R (2012) The plight of nuns: hazards of nulliparity. Lancet 379(9834):2322-2323

Burris S (1997) The invisibility of public health: population-level measures in a politics of market individualism. Am J Public Health 87:1607-1610

Carson JL, Madonna A, Owens M (2013) Partisan efficiency in an open-rule setting: the amending process in the U.S. senate, 1865-1945. Congress \& the Presidency 40(2):105-128

Condorcet ([1793] 1847) "Plan de Constitution, presenté a la convention nationale les 15 et 16 février 1793", Oeuvres, 12, 333-415

Donckier V, Lucidi V, Gustot T, Moreno C (2014) Ethical considerations regarding early liver transplantation in patients with severe alcoholic hepatitis not responding to medical therapy. J Hepatol 60:866-871

Gilbert MD (2006) Single subject rules and the legislative process. University of Pittsburgh Law Review 67:803870

Grüne-Yanoff T (2016) "Framing", pp. 189-215 in Sven Ove Hansson and Gertrude Hirsch Hadorn (eds.). Springer, The Argumentative Turn in Policy Analysis

Hansson SO (1996) Decision-making under great uncertainty. Philos Soc Sci 26:369-386

Hansson SO (2007) Philosophical problems in cost-benefit analysis. Econ Philos 23:163-183

Hansson SO (2010) The harmful influence of decision theory on ethics. Ethical Theory Moral Pract 13:585-593

Hansson SO (2013) The ethics of risk. Ethical analysis in an uncertain world. Palgrave Macmillan, New York

Hansson SO (2014) The moral Oracle's test. Ethical Theory Moral Pract 17:643-651

Hansson SO (2016) The ethics of economic decision rules. In: DeMartino GF, McCloskey DN (eds) The Oxford handbook of professional economic ethics. Oxford University Press, New York, pp 29-54

Hansson SO (2017) Ethical risk analysis. In: Hansson SO (ed) The Ethics of Technology. Methods and Approaches. Rowman and Littlefield, London, pp 157-171

Hansson SO, Oughton D (2013) Public participation-potential and pitfalls. In: Pp. 333-346 in Deborah Oughton and Sven Ove Hansson (eds.). Elsevier Science, Social and Ethical Aspects of Radiation Risk Management 
Hartung TK, Nash J, Ngubane N, Fredlund VG (2002) AIDS awareness and sexual behaviour in a high HIV prevalence area in rural northern Kwazulu-Natal, South Africa. Int J STD AIDS 13:829-832

Hirsch Hadorn G (2016) “Temporal strategies for decision-making”, pp. 217-242 in Sven Ove Hansson and Gertrude Hirsch Hadorn (eds) The Argumentative Turn in Policy Analysis. Reasoning about Uncertainty. Springer

Hoover KD (1990) The logic of causal inference. Econ Philos 6:207-234

Jeffrey R (1976) "Savage's omelet", PSA: Proceedings of the Biennial Meeting of the Philosophy of Science Association, Volume Two: Symposia and Invited Papers. University of Chicago Press, Chicago, pp 361-371

Johri M, Ubel PA (2003) Setting organ allocation priorities: should we care what the public cares about? Liver Transpl 9:878-880

Kupperman JJ (1980) Vulgar Consequentialism. Mind 89:321-337

Leong J, Im GY (2012) Evaluation and selection of the patient with alcoholic liver disease for liver transplant. Clinics in Liver Disease 16:851-863

Louise J (2004) Relativity of value and the consequentialist umbrella. Philos Q 54:518-536

Malone TW (2004) The future of work: how the new order of business will shape your organization, your management style, and your life. Harvard Business School Press, Boston

Mill JS ([1843] 1996) A system of logic. In: Collected works of John Stuart mill. London, vol 7. London: Routledge

Muldoon R (2013) Diversity and the division of cognitive labor. Philos Compass 8(2):117-125

Needleman HL (1998) Childhood lead poisoning: the promise and abandonment of primary prevention. Am J Public Health 88:1871-1877

Pettit P (1988) The consequentialist can recognize rights. Philos Q 38:42-55

Resnik MD (1987) Choices. An introduction to decision theory. University of Minnesota Press, Minneapolis

Sandell N, Varaiya P, Athans M, Safonov M (1978) Survey of decentralized control methods for large scale systems. IEEE Trans Autom Control 23(2):108-128

Sasco AJ, Secretan MB, Straif K (2004) Tobacco smoking and cancer: a brief review of recent epidemiological evidence. Lung Cancer 45(Suppl. 2):S3-S9

Scanlon TM (1998) What we owe to each other. Cambridge, Mass, Belknap

Seidenfeld T (1994) "When normal and extensive form decisions differ", pp. 451-463 in Dag Prawitz, Brian Skyrms, and Dag Westerståhl (eds) Logic and Philosophy of Science in Uppsala. Dordrecht: Kluwer

Sen A (1983) Evaluator-relativity and consequential evaluation. Philos Public Aff 12:113-132

Sen A (2000) Consequential evaluation and practical reason. J Philos 97:477-502

Skorupski J (1995) Agent-neutrality, consequentialism, utilitarianism... a terminological note. Utilitas 7:49-54

Sosa D (1993) Consequences of consequentialism. Mind 102:101-122

Stegeman I, Willems DL, Dekker E, Bossuyt PM (2014) Individual responsibility, solidarity and differentiation in healthcare. J Med Ethics 40(11):770-773

Thomson JJ (1986) Rights, restitution and risk: Essays in moral theory. Harvard University Press, Cambridge Mass

Thornton V (2009) Who gets the liver transplant? The use of responsibility as the tie breaker. J Med Ethics 35(12):739-742

Troyer H (1988) Review of cancer among 4 religious sects: evidence that life-styles are distinctive sets of risk factors. Soc Sci Med 26:1007-1017

Vaughn KI (1980) Economic calculation under socialism: the Austrian contribution. Econ Inq 18(4):535-554

Viscusi WK (2000) Risk equity. J Leg Stud 29:843-871

Waller BN (2005) Responsibility and health. Camb Q Healthc Ethics 14:177-188

Zamir T (2001) One consequence of consequentialism: morality and overdetermination. Erkenntnis 55:155-168 